\title{
EFFECT OF LIGHT-CURING UNITS AND ACTIVATION MODE ON POLYMERIZATION SHRINKAGE AND SHRINKAGE STRESS OF COMPOSITE RESINS
}

\author{
Lawrence Gonzaga LOPES ${ }^{1}$, Eduardo Batista FRANCO ${ }^{2}$, José Carlos PEREIRA ${ }^{3}$, Rafael Francisco Lia MONDELLI ${ }^{2}$
}

\begin{abstract}
1- PhD, Adjunt Professor, Department of Preventive and Oral Reabilitation, Dental School, Federal University of Goiás, Goiânia, GO, Brazil. 2- PhD, Associate Professor, Department of Operative Dentistry, Dental Materials and Endodontics, Bauru School of Dentistry, University of São Paulo, Bauru, SP, Brazil.

3- PhD, Professor, Department of Operative Dentistry, Dental Materials and Endodontics, Bauru School of Dentistry, University of São Paulo, Bauru, SP, Brazil.

Corresponding address: Prof. Dr. Eduardo B. Franco, Departamento de Odontologia Restauradora, Endodontia e Materiais Dentários,Faculdade de Odontologia de Bauru, Universidade de São Paulo. Alameda Dr. Octávio Pinheiro Brisolla 9-75 - 17012-901, Bauru, SP, Brasil - Phone: 55 14 3235-8265 - Fax: 5514 3235-8325 - e-mail: ebfranco@fob.usp.br
\end{abstract}

Received: April 17, 2007 - Modification: September 14, 2007 - Accepted: October 11, 2007

\begin{abstract}
$\Gamma_{\text {he }}$ The aim of this study was to evaluate the polymerization shrinkage and shrinkage stress of composites polymerized with a LED and a quartz tungsten halogen (QTH) light sources. The LED was used in a conventional mode (CM) and the QTH was used in both conventional and pulse-delay modes (PD). The composite resins used were Z100, A110, SureFil and Bisfil 2B (chemical-cured). Composite deformation upon polymerization was measured by the strain gauge method. The shrinkage stress was measured by photoelastic analysis. The polymerization shrinkage data were analyzed statistically using two-way ANOVA and Tukey test $(\mathrm{p} \leq 0.05)$, and the stress data were analyzed by one-way ANOVA and Tukey's test $(\mathrm{p} \leq 0.05)$. Shrinkage and stress means of Bisfil 2B were statistically significant lower than those of Z100, A110 and SureFil. In general, the PD mode reduced the contraction and the stress values when compared to CM. LED generated the same stress as QTH in conventional mode. Regardless of the activation mode, SureFil produced lower contraction and stress values than the other light-cured resins. Conversely, Z100 and A110 produced the greatest contraction and stress values. As expected, the chemically cured resin generated lower shrinkage and stress than the light-cured resins. In conclusion, The PD mode effectively decreased contraction stress for Z100 and A110. Development of stress in light-cured resins depended on the shrinkage value.
\end{abstract}

Uniterms: Dental materials. Polymerization shrinkage. Composite resins. Stress. Light emitting diode. Halogen light.

\section{INTRODUCTION}

Tooth-colored composites have been widely used as restorative materials for anterior and posterior restorations. This reaction occurs by formation of covalent bonds during monomer conversion. Complete shrinkage can be divided into pre-gel and post-gel phases. During pre-gel polymerization, the composite flows and stresses within the structure are relieved ${ }^{9,18,33}$. Consequently, post-gel polymerization results in significant stress in the surrounding tooth structure and composite/tooth interface ${ }^{21,26,33}$. Additionally, stresses arising from polymerization shrinkage may contribute to postoperative pain, microleakage and recurrent caries $^{37}$.

Manufacturers have recommended high light intensity to render a higher degree of monomer conversion into polymer, thus improving the mechanical properties of composite resins. Unfortunately, the degree of conversion is always proportionally associated with shrinkage and a high rate of polymerization ${ }^{2,9}$. Clinically, the effect of postgel shrinkage and contraction stress can be minimized by flow during setting by applying short pulses of energy (pulse activation) or pre-polymerization at low-intensity light followed by a final cure at high intensity (soft-start techniques) ${ }^{3,33}$, as these methods promote a longer pre-gel phase in light-cured composites.

The visco-elastic properties, such as polymerization shrinkage, polymerization reaction rate and modulus of elasticity are very important in the pattern of contraction stress $^{18,32}$. Thus, the different formulations of composite resins, such as amount and type of resin matrix, filler level, and quantity of initiator and inhibitor should be considered in the contraction stress development ${ }^{23}$.

Despite their popularity, the use of halogen light-curing units (LCUs) to polymerize dental composites has several setbacks ${ }^{33}$. The halogen bulbs, reflector, and filter degrade 
over time due to high operation temperatures and heat produced, resulting in a limited effective lifetime of about 40 to 100 hours ${ }^{16,27}$. Current LCUs using blue light emitting diodes (LEDs) have shown advantages, namely lower temperature, long lifetime, no filters, resistance to shock and vibration and narrow spectral output $(440-490 \mathrm{~nm})$ that falls within the camphoroquinone (CQ) absorption spectrum $^{27,33,35,38}$. Because its is relatively new in dentistry, the effect of LED light on polymerization shrinkage and stress is not well reported in the dental literature. The aim of the present study was to test the hypothesis that there is no statistically significant difference in post-gel shrinkage and polymerization stress produced by halogen and LED LCUs for photocuring diferent composite resins. The second aim was to test the hypothesis that there is no statistically significant difference in conventional, pulse and chemical curing modes: and the last was to test the hypothesis that four commercially composite resins are equivalent among them.

\section{MATERIALS AND METHODS}

One chemically and three light-cured composite resins with different formulations were used in this study: a hybrid composite, Z100 (3M/ESPE, St. Paul, MN, USA; shade A2, Lot 2BA); a hybrid "packable", SureFil (Dentsply, Milford, DE, USA; shade A, Lot 010423); a microfilled composite, A110 (3M/ESPE, shade A2, Lot 2BL), and Bisfil 2B chemically cured composite (Bisco Inc., Schaumburg, IL, USA universal shade, Lot 0100003796-base and 0100004129-catalyst). The composition of these materials is presented in Table 1. The chemically cured resin composite was used according to the manufacturer's instructions. A conventional LCU (QTH; Bisco Inc.) that allowed for independent command over time and power density (VIP- variable intensity polymerizer) and a first-generation LED LCU (Dabi Atlante, Ribeirão Preto, $\mathrm{SP}$, Brazil; $130 \mathrm{mw} / \mathrm{cm}^{2}$ power density and 450-480 nm wavelength) were used. The polymerization shrinkage and stresses generated during polymerization of the composite

TABLE 1- Description of the composition of the tested restorative composite resins

\begin{tabular}{|c|c|c|}
\hline Material & Composition & Batch numbers \\
\hline Z100 & $\begin{array}{l}\text { Bis-GMA, TEGDMA; Zirconia, silica } \\
\text { Filler volume: } 66 \% \\
\text { Filler weight: } 84.5 \%\end{array}$ & 2BA \\
\hline A110 & $\begin{array}{l}\text { Bis-GMA, TEGDMA; Silica } \\
\text { Filler volume: } 40 \% \\
\text { Filler weight: } 56 \%\end{array}$ & $2 \mathrm{BL}$ \\
\hline SureFil & $\begin{array}{l}\text { Modified Bis-GMA, urethane resin; Silanized barium, boro- } \\
\text { silicate-aluminium } \\
\text { Filler volume: } 65 \% \\
\text { Filler weight: } 82 \%\end{array}$ & 010423 \\
\hline Bisfil 2B & $\begin{array}{c}\text { Bis-GMA, BIS-EMA; Amorphous silica, (base); TEGDMA; } \\
\text { Silica, glass frit (catalyst) } \\
\text { Filler volume: - } \\
\text { Filler weight: } 75 \%\end{array}$ & $\begin{array}{l}\text { Base- 0100003796; } \\
\text { Catalyst -0100004129 }\end{array}$ \\
\hline
\end{tabular}

TABLE 2- Description of the experimental groups and polymerization modes

\begin{tabular}{llll}
\hline Groups & Composite resins & Polymerization mode & Time and intensities \\
\hline Group 1Z & Z100 & Conventional mode (CM)-QTH & 60 seconds- $600 \mathrm{~mW} / \mathrm{cm}^{2}$ \\
Group 1A & A110 & \\
Group 1S & SureFil & Conventional mode - LED & \\
Group 2Z & Z100 & & 60 seconds- $130 \mathrm{~mW} / \mathrm{cm}^{2}$ \\
Group 2A & A110 & & \\
Group 2S & SureFil & Pulse Delay Mode (PD)-QTH & 3 seconds-200 $\mathrm{mW} / \mathrm{cm}^{2} ;$ \\
Group 3Z & Z100 & & 3 min. hiatus; \\
Group 3A & A110 & 59 seconds- $600 \mathrm{~mW} / \mathrm{cm}^{2}$ \\
Group 3S & SureFil & & \\
Group 4 & Bisfil 2B & Chemical-cured & \\
\hline
\end{tabular}


resin were determined using a strain gauge and by photoelastic analysis, respectively ${ }^{21,31}$.

\section{Polymerization Shrinkage Evaluation}

The curing conditions and experimental groups are listed in Table 2. A silicone circular mold (inner diameter $5 \mathrm{~mm}$ and height $2.0 \mathrm{~mm}$ ) was used and a glass slide served as the base for the set-up. A foil electrical resitance strain gauge (KFG-02-120-C1-11, Kyowa, lot Y331/064A, Japan) was attached to the flat glass surface. The gauge was $2 \mathrm{~mm}$ long, had an electrical resistance of $120 \mathrm{~W}$ and gauge factor 2.00 . With the strain gauge in place, the composite resin was placed in the cavity of the silicone frame. Care was taken to ensure that the silicone mould was completely filled. A glass slide was then placed on the top of the Mylar strip for five seconds and composite resin excess was removed. The leads from the strain gauge were connected to a strain-monitoring device (SC- 2043-SG, National Instruments Corp., Austin, TX, USA) that was connected to a data acquisition system (PCI - MIO - 16XE - 50, National Instruments Corp.) and initially balanced at zero. The data obtained were analyzed with LabView software (National Instruments Corp.). The composite specimes were polymerized as described in Table 1. Dimensional changes during and after light-curing was monitored at a controlled temperature $\left(22.5 \pm 1^{\circ} \mathrm{C}\right)$. During the curing process, shrinkage measurements were taken continuously at every one second. Polymerization shrinkage measurements were taken immediately after application of the light source and after 15 minutes. Five composite specimens were used for each group. Data were obtained as microstrain and were subjected to two-way ANOVA and Tukey's test at 0.05 significance level.

\section{Stress shrinkage evaluation}

The photoelastic material used in this study was a transparent epoxy resin (Cristal 2120- Redelease, São Paulo, SP, Brazil $)^{10}$. Box-shaped cavities simulating a class I preparation ( $5 \mathrm{~mm}$ long X, $3 \mathrm{~mm}$ wide X $2 \mathrm{~mm}$ deep) were prepared by placing a transparent resin into a silicone mould containing the previously determined dimensions ${ }^{21}$ (Figure 1). Dimentions of a class I cavity were selected because of the strict $\mathrm{C}$-factor of 3.1. One layer of the adhesive resin Scotchbond Multi Purpose (3M/ESPE) was applied to the inner walls of the class I cavities, and light-cured for $20 \mathrm{~s}$ with a visible light curing unit (VIP, Bisco Inc.) using a standardized output $\left(600 \mathrm{~mW} / \mathrm{cm}^{2}\right)$. This pretreatment allowed slight bonding of the light-cured resin to the photoelastic material.

In this part of the study, the experimental design was modified as separated groups were tested according to demonstrated in Tables 4 and 5. Composite resin was bulk filled into the cavity and cured with different polymerization modes: Z100: QTH- conventional mode-CM (60 seconds$\left.600 \mathrm{~mW} / \mathrm{cm}^{2}\right)$; LED- conventional mode- CM (60 seconds $130 \mathrm{~mW} / \mathrm{cm}^{2}$ ); QTH-pulse delay mode- PD (3 seconds-200 $\mathrm{mW} / \mathrm{cm}^{2} ; 3 \mathrm{~min}$. hiatus; 59 seconds $\left.-600 \mathrm{~mW} / \mathrm{cm}^{2}\right)$; and chemical resin that was a control group; A110: QTH- CM; LED-CM; QTH-PD; and chemical-cured resin; SureFil: QTH-

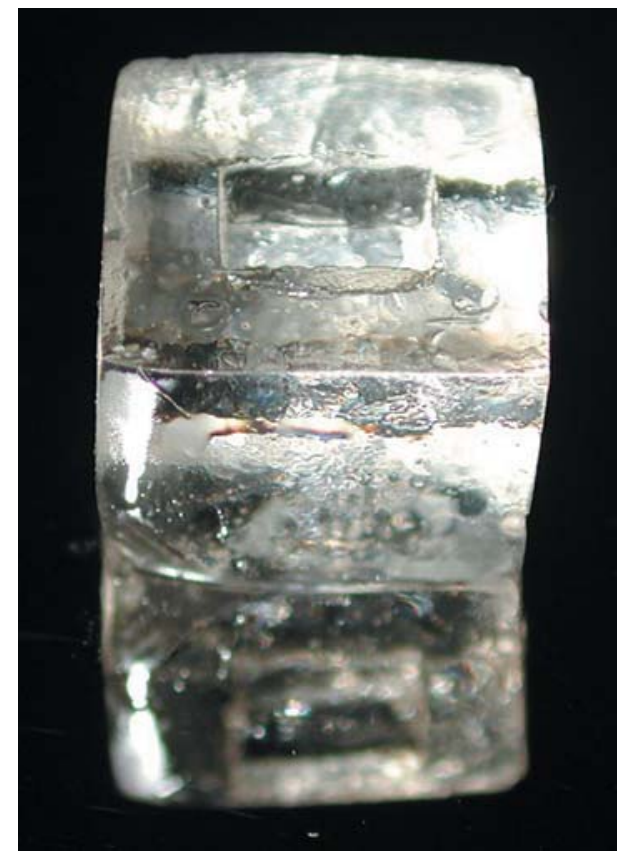

FIGURE 1- Box-shaped cavities simulating a class I preparation in transparent resin

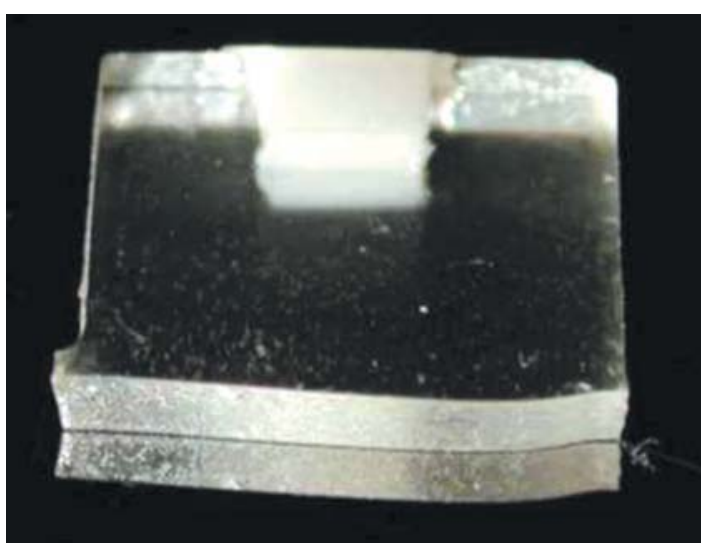

FIGURE 2- Cross-sectioned specimens for photoelastic analysis

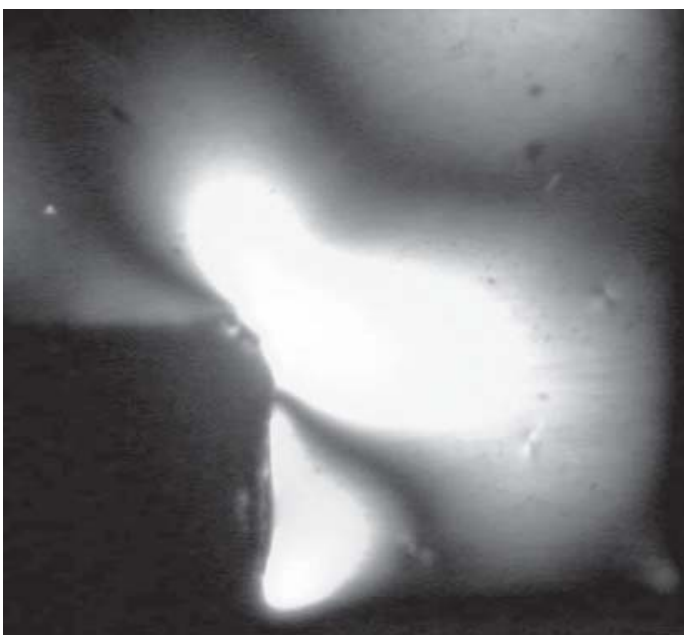

FIGURE 3- Stress area recorded in black field for determination the contraction stress 


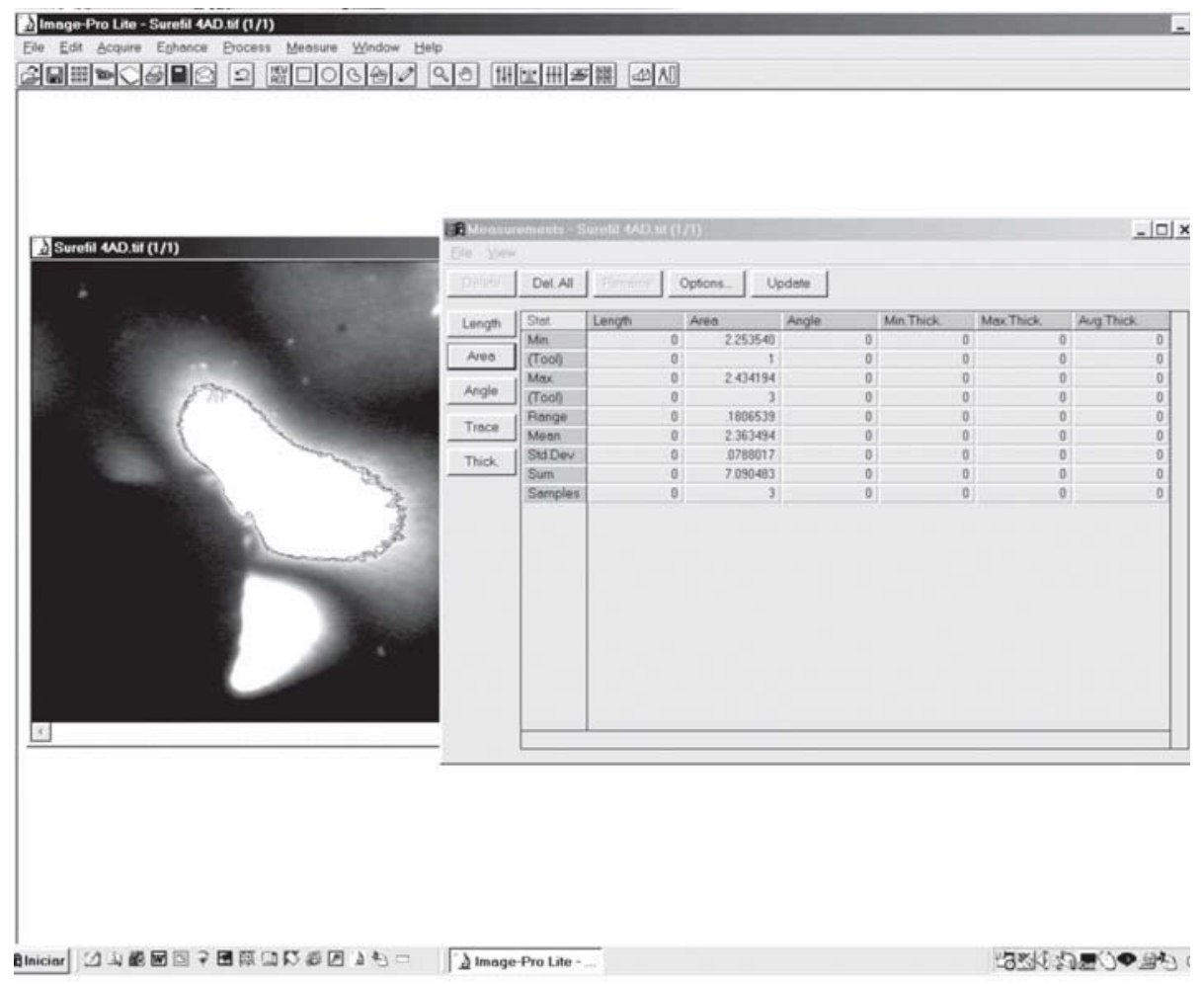

FIGURE 4- Image of specime in the software used to measure each picture fringe area by delimitation of the stress area

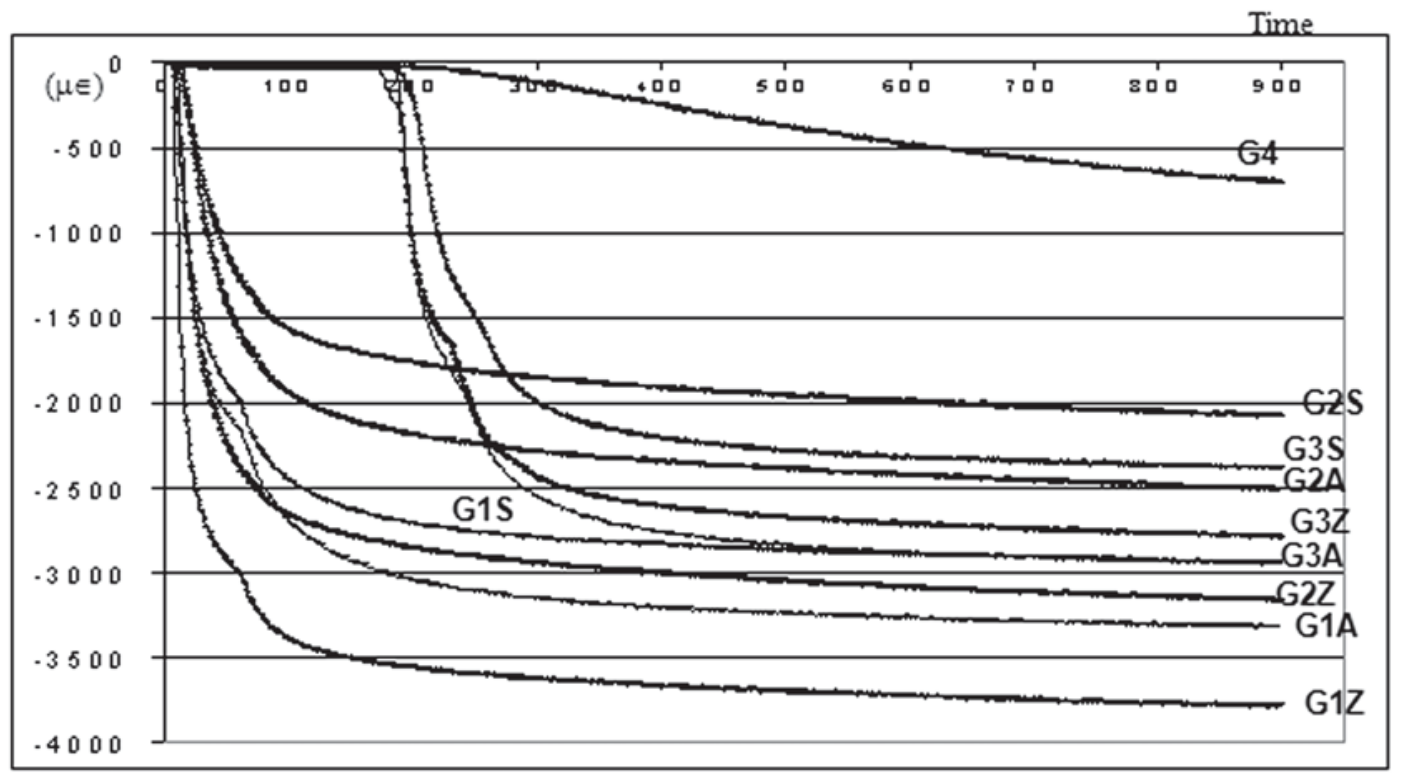

FIGURE 5- Shrinkage strain resulting from polymerization contraction of the experimental groups

CM; LED-CM; QTH-PD; and chemically cured resin. For evaluation of the stress behavior of the composite resins, two curing regimens were selected: QTH-CM: Z100, A110, SureFil, and chemically cured resin that was the control group; QTH-PD: Z100; A110; SureFil and chemically cured resin. The LED-CM was not adopted for evaluation of the composite resins because the results of the pilot study were comparable to those of QTH-CM. Immediately after curing, a section of photoelastic specimen $(2.0 \mathrm{~mm}$ in thickness) was cut perpendicularly to the long axis of the cavity with a water-cooled diamond saw (Extec Co., Enfield, CT, USA) and was polished with 1200- and 2000-grit abrasive papers (3M, Ribeirão Preto, São Paulo, Brasil) under running water (Figure 2). The experiment was carried out at $23^{\circ} \mathrm{C} \pm 2{ }^{\circ} \mathrm{C}$. Seven sections were obtained for each group. Isochromatic fringes were analyzed under a polarized light microscope (Carl-Zeeiss, Germany), which contained a video-camera. The images were immediately transferred to a computer and were recorded in both color and black fields. The black field was used because it generates greater definition of stress 
areas making the measurement of these areas possible because stress in the photoelastic resin is only seen in one evident color (Figure 3). Only isochromatics fringes were obtained since the microscopic contained two 1/4-foiles between the sample and the analyzer and the polarizer, working as circular polariscope. As the stresses produced by composite resins on the cavity walls are directly proportional to the area of fringes, the total stress was determined by measurement of these areas, which was given in square millimeters $\left(\mathrm{mm}^{2}\right)$. For these stress areas of evaluation, a specific software (Image-Pro lite, 4.0 version; Media Cybernetics, Bethesda, MD, USA) was used to measure the each picture fringe area by delimitation of the stress area contorniate (Figure 4). Three readings were made for each area. The data for each group were analyzed by

TABLE 3- Experimental groups and mean values of strain shrinkage $(n=5)$ after 15 minutes ( $\mu$ strain)

\begin{tabular}{ll} 
Groups & Strain shrinkage ( \pm SD) \\
\hline G1Z (QTH-CM-Z100) & $-3703.06168 .5^{\mathrm{a}}$ \\
G1A (QTH-CM-A110) & $-3309.83208 .2^{\mathrm{ba}}$ \\
G1S (QTH-CM-SureFil) & $-2933.51169 .1^{\mathrm{c}}$ \\
G2Z (LED-CM-Z100) & $-3153.59168 .5^{\mathrm{dbc}}$ \\
G2A (LED-CM-A110) & $-2499.14208 .9^{\mathrm{e}}$ \\
G2S (LED-CM-SureFil) & $-2066.31124 .8^{\mathrm{fe}}$ \\
G3Z (QTH-PD-Z100) & $-2779.52218 .0^{\mathrm{gcde}}$ \\
G3A (QTH-PD-A110) & $-2937.49107 .9^{\mathrm{hbcdg}}$ \\
G3S (QTH-CM-SureFil) & $-2370.67230 .9^{\text {ief }}$ \\
G4 (Chemical-cured) & $-670.41128 .9^{\mathrm{j}}$
\end{tabular}

Same letters $=$ no statistically significant difference; $p<0.05$. one-way ANOVA and multiple comparisons were performed by Tukey's test at $\mathrm{p}<0.05$.

\section{RESULTS}

Table 3 and Figure 5 show the mean linear shrinkage during the polymerization process for the different groups studied. The stress areas $\left(\mathrm{mm}^{2}\right)$ obtained with the groups are shown in Tables 4 and 5. The chemically cured composite resin produced the lowest shrinkage strain and stress $(\mathrm{p}<0.05)$. No shrinkage was observed during the initial fourminutes of chemical reaction (Figure 5). For light-cured composites, shrinkage occurred immediately after light polymerization when cured in conventional mode (Figure 5). For Z100 composite the QTH-CM exhibited significantly higher shrinkage than LED-CM and QTH-PD mode $(\mathrm{G} 1>\mathrm{G} 2>\mathrm{G} 3)$. For A110 resin the LED-CM demonstrated significantly lower shrinkage, while no significant differences between QTH-CM and QTH-PD modes were found. Conversely, for SureFil, high shrinkage values were produced by QTH-CM, while no significant differences were observed between LED-CM and QTH-PD modes. Regarding the stress data for Z100, it was observed that the QTH-CM demonstrated significantly higher value than LED-CM and QTH-PD modes. However, the QTH-PD mode produced significantly lower stress value than other light-activated modes $(\mathrm{p}<0.05)$. For A110 and SureFil, the QTH-CM and LED-CM exhibited significantly higher stress than QTH-PD mode $(\mathrm{p}<0.05)$. In general, the PD mode reduced the contraction and stress values when compared to $\mathrm{CM}$. SureFil composite, independently of the activation mode, showed the lowest shrinkage strain and stress when compared to $\mathrm{Z} 100$ and A110 composites $(\mathrm{p}<0.05)$. In general, Z100 and A110 showed similar results with greatest contraction strain and stress.

TABLE 4- Experimental groups comparing the activation mode for each light-cured composite resin and mean of stress areas $\left(\mathrm{mm}^{2}\right)$

\begin{tabular}{lllll}
\hline Material & QTH-CM & LED-CM & QTH-PD & Control- Bisfil 2B \\
\hline Z100 & $5.7 \pm(0.58)^{\mathrm{a}}$ & $6.4 \pm(0.24)^{\mathrm{b}}$ & $4.8 \pm(0.37)^{\mathrm{c}}$ & $3.2 \pm(0.58)^{\mathrm{d}}$ \\
A110 & $7.1 \pm(0.38)^{\mathrm{a}}$ & $7.3 \pm(0.40)^{\mathrm{a}}$ & $6.1 \pm(0.67)^{\mathrm{b}}$ & $3.1 \pm(0.62)^{\mathrm{c}}$ \\
SureFil & $3.9 \pm(0.72)^{\mathrm{a}}$ & $4.2 \pm(0.45)^{\mathrm{a}}$ & $3.7 \pm(0.63)^{\mathrm{ab}}$ & $2.8 \pm(0.79)^{\mathrm{cb}}$ \\
\hline
\end{tabular}

Same letters in horizontal line $=$ no statistically significant difference $; p<0.05$.

TABLE 5- Experimental groups and mean of stress areas $\left(\mathrm{mm}^{2}\right)$

\begin{tabular}{lllll}
\hline Photo-actvate mode & Z100 & A110 & SureFil & Control- Bisfil 2B \\
\hline QTH-CM & $9.1 \pm(0.40)^{\mathrm{a}}$ & $8.5 \pm(0.71)^{\mathrm{a}}$ & $7.3 \pm(0.30)^{\mathrm{b}}$ & $5.6 \pm(1.2)^{\mathrm{c}}$ \\
QTH-PD & $8.1 \pm(0.65)^{\mathrm{a}}$ & $7.8 \pm(0.58)^{\mathrm{a}}$ & $7.0 \pm(0.39)^{\mathrm{b}}$ & $4.0 \pm(0.50)^{\mathrm{c}}$ \\
\hline
\end{tabular}

Same letters in horizontal line $=$ no statistically significant difference; $p<0.05$. 


\section{DISCUSSION}

Polymerization shrinkage is considered a major problem with resin-based materials because it creates destructive stresses when the material is bonded to cavity walls ${ }^{26}$. In order to extend the pre-gel phase of the light-cured resins, the intensity of the light and the polymerization rate should be modified to allow molecular rearrangements and decrease of the polymerization contraction stress. The strain gauge method utilized in this study for determination of polymerization shrinkage is able to record the deformation in real time ${ }^{31}$. For contraction stress evaluation, the photoelastic method was used since it is suitable to visualize the contraction stress areas ${ }^{10}$. For this part of the evaluation, an early pilot study found that even a small variation in the proportion or manipulation of the transparent resin would produce different results. Therefore, the experimental design was modified until reproducible results were obtained.

The results of this study indicated that the pulse delay mode (QTH) yielded low shrinkage values and stress as compared to the other curing modes studied. Thus, the second hypothesis was rejected. This can be explained due to the low initial energy density applied followed by a final high energy light irradiation, allowing flowing of the material between two pulses. During that initial phase of polymerization, in which the newly formed polymer is still in a flexible state, the stress developed from shrinkage can be relieved by flow of the composite, reducing the stress at the tooth/resin interface ${ }^{17,29}$. The long pre-gel phase occurs in chemically cured composite resins, in which the reaction happens slowly and with a prolonged low modulus phase $^{12,13,15}$. Conversely, with light-cured composite resins, there is no pre-gel phase because of its rapid polymerization upon light activation, consequently allowing less resin flow $^{8,17}$. The results with chemically cured composite resin confirmed this theory (long pre-gel phase), since the strain data showed a lower rate of polymerization and a lower strain mean than light-cured composites when cured by conventional mode. In addition, Bisfil $2 \mathrm{~B}$ produced the lowest stress areas in the photoelastic analysis. Kinomoto, et al. ${ }^{20}(1999)$ reported that the main reason for the difference in the magnitudes of the internal stresses between chemically cured and light-cured composites in their study was considered to be that the rate of polymerization of the lightcured composite is much higher than that of the chemically cured composite. The explanation is related to the polymerization of the resin matrix that produces a gelation in which the restorative material is transformed from a viscous-plastic phase with flow into a rigid-elastic phase $\mathrm{e}^{6,22,36}$. The pulse delay mode uses the same rationale for reducing the stress ${ }^{17,29}$.

The first hypothesis of this study was also rejected for shrinkage evaluation. The low contraction rates produced by the LED LCU are explained by its low irradiance and low heat generated. The unit used in this study is classified as a first-generation device because the output is limited and the double-bond conversion is compromised ${ }^{14,25,34}$. For A110 resin, the LED LCU produced lower shrinkage values than
QTH in conventional and pulse delay modes. This result can be explained by the greater attenuation and scattering of light by the submicron filler particles than other lightcured resins, requiring more energy for adequate polymerization ${ }^{4,11,30}$. For contraction stress evaluation, the first hypothesis was confirmed since the contraction stress data showed that, in general, the QTH in conventional mode produced similar stress to LED. The explanation for these results could be due to the polymerization rate since the LED produces wavelengths with a narrow spectrum that falls within CQ absorption spectrum resulting in an immediate chemical reaction similar to the QTH in conventional mode. Therefore, despite the low power output emitted by the firstgeneration LED and low contraction rate produced, this LCU produces a rapid polymerization reaction that permits less resin flow, affecting the stress production.

The chemical composition of composite materials is directly related to their viscoelastic properties ${ }^{7,24}$. Properties, such as elastic modulus and shrinkage strain, have an important relationship with stress development. Strain induces a proportional stress (s) according to Hooke's law, $\mathrm{s}=\mathrm{e}$. E, in which e is the relative strain and $\mathrm{E}$ is the Young ' $\mathrm{s}$ modulus of the restorative material. Therefore, higher stiffness leads to increased stress for a given shrinkage strain. The opposite is also true, as the amount of shrinkage strain also plays an important role in generating stress in dental composite restorations ${ }^{7}$. The increase in the filler level will contribute to a reduced shrinkage strain because the overall polymerization shrinkage depends on the amount of polymer matrix ${ }^{7}$. On the other hand, the stiffness of the composite is also increased at high filler levels ${ }^{24}$. Comparing the three light-cured composite resins, Z100 (hybrid), A110 (microfilled) and SureFil ("packable"), different properties such as, shrinkage strain and stress development, should be observed. Thus, the third hypothesis was partially accepted because the results of this study demonstrated that the Z100 and A110 composites produced the highest shrinkage strain values and stress areas and were not different to each other. However, SureFil composite showed the lowest shrinkage strain mean and stress area. Although SureFil ("packable") presents a high stiffness, it produced the lowest stress areas. Conversely, A110 (microfilled) presented reduced stiffness, however, it generated greater stress areas as compared to SureFil. Therefore, it is very important to consider the shrinkage value of composite resins and not elastic modulus alone. The composite Z100 has Bis-GMA (Bisphenol-glycidyl methacrylate) monomer diluted with TEGDMA (triethylene glycol dimethacrylate) and the content of the filler is greater $(66 \%$ in volume;Table $1)$. The high shrinkage strain verified by Z100 may be explained by the presence of the TEGDMA molecule, which has low molecular weight, high mobility and low viscosity, producing high polymerization shrinkage $e^{5,28}$. The high strain data verified with A110 composite can be explained by its composition, since it presents a high content of organic matrix (Table 1). Z100 and A110 composites showed the highest means of stress areas, despite different stiffness (21 GPA ${ }^{1}$ - and 7 GPA- Technical Profile-3M, respectively). 
These results can be related to the development of high shrinkage strain by A110 composite. Conversely, the lower stress area mean produced by SureFil is related to the low shrinkage strain generated, since this material presents high filler load (66\% in volume-Table 1). Some of these findings are supported by Ernst, et al. ${ }^{10}$ (2000), who observed low stress with a low-shrinkage composite resin.

\section{CONCLUSIONS}

The chemically cured composite provided the lowest shrinkage strain and stress means. The pulse delay (QTH) mode was effective to decrease the contraction stress. The conventional mode with QTH and LED produced the higher stress means. Otherwise, Z100 and A110 produced the highest shrinkage strain and stress means. Among the lightcured composites, SureFil generated the lowest shrinkage strain and stress area means.

\section{ACKNOWLEDGEMENTS}

The authors would like to thank Profa. Patrícia Pereira for her assiatance in the preparation of this manuscript. The authors are also grateful to Prof. José Henrique Rubo for his support in strain gauge test instrument.

\section{REFERENCES}

1- Abe Y, Lambrechts P, Inoue S, Braem MJ, Takeuchi M, Vanherle G, et al. Dynamic elastic modulus of "packable" composites. Dent Mater. $2001 ; 17: 520-5$

2- Asmussen E, Peutzfeldt A. Influence of composition on rate of polymerization contraction of light-curing resin composites. Acta Odontol Scand. 2002;60:146-54

3- Bouschlicher MR, Rueggeberg FA. Effect of ramped light intensity on polymerization force and conversion in a photoactivated composite. J Esthet Dent. 2000;12:328-39.

4- Caughman WF, Rueggeberg FA. Shedding new light on composite polymerization. Oper Dent. 2002;27:636-8.

5- Cehreli MC, Canay S. Comparison of post-gel shrinkage strains in light-polymerized composite resins. J Prosthet Dent. 2002;88:4616.

6- Chen HY, Manhart J, Hickel R, Kunzelmann KH. Polymerization contraction stress in light-cured packable composite resins. Dent Mater. 2001;17:253-9.

7- Choi KK, Condon JR, Ferracane JL. The effects of adhesive thickness on polymerization contraction stress of composite. J Dent Res. 2000;79:812-23.

8- Dauviller BS, Feilzer AJ, De Gee AJ, Davidson CL. Visco-elastic parameters of dental restorative materials during setting. J Dent Res. 2000;79:818-23.

9- Davidson CL, De Gee AJ. Light-curing units, polymerization, and clinical implications. J Adhes Dent. 2000;2:167-73.
10- Ernst CP, Kürschner R, Rippin G, Willershausen B. Stress reduction in resin-based composites cured with a two-step light-curing unit. Am J Dent. 2000;13:69-72.

11 - Fleming GJ, khan S, Afzal O, Palin WM, Burke FJ. Investigation of polymerization shrinkage strain, associated cuspal movement and microleakage of MOD cavities restored incrementally with resinbased composite using an LED light curing unit. J Dent. 2007;35:97103.

12 - Fusayama T. Indications for self-cured and light-cured adhesive composite resins. J Prosthet Dent. 1992;67:46-51.

13- Garberoglio E, Coli P, Brännström M. Contraction gaps in class II restorations with self-cured and light-cured resin composites. Am J Dent. $1995 ; 8: 303-7$

14- Hofmann N, Hugo B, Klaiber B. Effect of irradiation type (LED or QTH) on photo-activated composite shrinkage strain kinetics, temperature rise, and hardness. Eur J Oral Sci. 2002;110:471-9.

15- Hofmann N, Markert T, Hugo B, Klaiber B. Effect of high intensity vs. Soft-start halogen irradiation on light-cured resin-based composites. Part I: temperature rise and polymerization shrinkage. Am J Dent. 2003;16:421-30.

16- Jandt KD, Mills RW, Blackwell GB, Ashworth SH. Depth of cure and compressive strength of dental composites cured with blue light emitting diodes (LEDs). Dent Mater. 2000;16:41-7.

17- Kanca J, Suh BI. Pulse activation: reducing resin-based composite contraction stresses at the enamel cavosurface margins. Am J Dent. 1999; $12: 107-12$

18- Kemp-Scholte CM, Davidson CL. Marginal sealing of curing contraction gaps in class $\mathrm{V}$ composite resin restorations. J Dent Res. 1998;67:841-5.

19- Kinomoto Y, Torii M, Takeshige F, Ebisu S. Polymerization contraction stress of resin composite restorations in a model class I cavity configuration using photoelastic analysis. J Esthet Dent. 2000;12:309-19.

20- Kinomoto Y, Torii M, Takeshige F, Ebisu S. Comparison of polymerization contraction stresses between self- and light-curing composites. J Dent. 1999;27:383-9.

21 - Kinomoto Y, Torii M. Photoelastic analysis of polymerization contraction stresses in resin composite restorations. J Dent. 1998;26:165-71.

22 - Krejci I, Planinic M, Stavridakis M, Bouillaguet S. Resin composite shrinkage and marginal adaptation with different pulse-delay light curing protocols. Eur J Oral Sci. 2005;113:531-6.

23-Labella R, Lambrechts P, Van Meerbeek B, Vanherle G. Polymerization shrinkage and elasticity of flowable composites and filled adhesives. Dent Mater. 1999;15:128-37.

24- Lambrechts P, Braem M, Vanherle G. Buonocore memorial lecture: evaluation of clinical performance for posterior composite resins and dentin adhesives. Oper Dent. 1987;12:53-78.

25-Leonard DL, Charlton DG, Roberts HW, Cohen ME. Polymerization efficiency of LED curing lights. J Esthet Restor Dent. 2002;14:286-95.

26- Lim BS, Ferracane JL, Sakaguchi RL, Condon JR. Reduction of polymerization contraction stress for dental composites by two-step light-activation. Dent Mater. 2002;18:436-44. 
27- Nitta K. Effect of light guide tip diameter of LED-light curing unit on polymerization of light-cured composites. Dent Mater. $2005 ; 21: 217-23$

28- Obici AC, Sinhoreti MA, de Goes MF, Consani S, Sobrinho LC. Effect of the photo-activation method on polymerization shrinkage of restorative composites. Oper Dent. 2002;27:192-8.

29- Pfeifer CS, Braga RR, Ferracane JL. Pulse-delay curing: influence of initial irraciance and delay time on shrinkage stress and microhardness of restorative composites. Oper Dent. 2006;31:6105 .

30- Price RBT, Felix CA, Andreou P. Evaluation of a secondgeneration LED curing light. J Can Dent Assoc. 2003;69:666.

31 - Sakaguchi RL, Douglas WH, Peters MCRB. Curing light performance and polymerization of composite restorative materials. J Dent. 1992;20:183-8

32- Sakaguchi RL, Wiltbank BD, Murchison CF. Contraction force rate of polymer composites is linearly correlated with irradiance. Dent Mater. 2004;20:402-7.

33- Soh MS, Yap AUJ, Siow KS. Post-gel shrinkage with different modes of LED and halogen light curing lights. Oper Dent. $2004 ; 29: 317-24$

34- Tarle Z, Knezevic A, Demoli N, Meniga A, Sutaloa J, Unterbrink $\mathrm{G}$, et al. Comparison of composite curing parameters: effects of light source and curing mode on conversion, temperature rise and polymerization shrinkage. Oper Dent. 2006;31:219-26.

35- Uhl A, Mills RW, Rzanny AE, Jandt KD. Time dependence of composite shrinkage using halogen and LED light curing. Dent Mater. $2005 ; 21: 278-86$.

36- Witzel MF, Calheiros FC, Gonçalves F, Kawano Y, Braga RR. Influence of photoactivation method on conversion, mechanical properties, degradation in ethanol and contraction stress of resinbased materials. J Dent. 2005;33:773-9.

37- Yap AUJ, Soh MS, Siow KS. Post-gel shrinkage with pulse activation and soft-start polymerization. Oper Dent. 2002;27:81-7.

38- Ye Q, Wang Y, Williams K, Spencer P. Characterization of photopolymerization of dentin adhesives as a function of light source and irradiance. J Biomed Mater Res B Appl Biomater. 2007;80:4446. 